\title{
THE ULTRASONOGRAPHIC FINDINGS OF THE LIVER, GALL BLADDER AND THEIR RELATED VASCULATURES IN HEALTHY EGYPTIAN BUFFALOES (BUBALUS BUBALIS)
}

\author{
ARAFAT KHALPHALLAH ${ }^{1}$, MOHAMMED ABDELHAKIEM ${ }^{2}$ and ENAS ELMELIGY ${ }^{3}$ \\ ${ }^{1}$ Department of Animal Medicine, Faculty of Veterinary Medicine, Assiut University, Assiut 71526, Egypt. \\ ${ }^{2}$ Department of Surgery, Anesthesiology and Radiology, Faculty of Veterinary Medicine, Assiut University, Assiut 71526, \\ Egypt. \\ ${ }^{3}$ Veterinary Teaching Hospital, Faculty of Veterinary Medicine, Assiut University, Assiut 71526, Egypt.
}

Received: 28 March 2016; Accepted: 28 April 2016

\begin{abstract}
This study provided a full description of the normal ultrasonographic findings of the hepatobiliary system and its blood vessels in Egyptian buffaloes. The reported results particularly those of ultrasonography were compared with the normal reference values of cattle that had been previously recorded. This study was carried out on thirty healthy buffaloes. Complete clinical examination, hematological pictures profiling, blood biochemical analysis of total blood serum proteins, albumins, globulins, aspartate aminotransferase (AST), alkaline phosphatase (AP), $\gamma$-glutamyltranspeptidase (GGT), triglycerides and cholesterol, radiography and ultrasonographic examination were conducted with all these animals. The results showed that the clinical findings, blood pictures and blood biochemical levels agreed with the previously reported reference values of healthy buffaloes. The outlines of cranial abdomen, line of diaphragm and the cardiac silhouette were displayed normally on the radiographs. The acoustic windows for ultrasonographic examination of the hepatobilliary system was the right 11 th intercostal space. The gall bladder could not be imaged from the right 12 th intercostal space. The description of these normal ultrasonographic findings of the aforementioned organs will be valuable in detection of the abnormalities of these organs.
\end{abstract}

Key words: Buffaloes, Gall bladder, Liver, Ultrasonography.

\section{INTRODUCTION}

The applications of ultrasonography in cows include the diagnosis of cardiac (Schweizer et al., 2003), abdominal (traumatic reticuloperitonitis, liver abscess, ileus of small intestine, caecal dilatation, abomasal displacement) (Braun et al., 1993b; Braun et al., 1995a, b, c; Hassel et al., 1995; Kim et al., 1996; Pusterla and Braun, 1997; Braun et al., 1997a; Braun et al., 1997b; Braun et al., 1998a; Braun et al., 1998b; Braun et al., 2002) and musculoskeletal affections (Kofler, 1996).

Ultrasonography had been applied as routine work for a diagnostic procedure for about 5 years in dogs (Nyland et al., 1986) and horses, (Rantanen, 1986), with hepatic diseases. In cattle, because the existing diagnostic tools for discovering liver diseases, such as the determination of specific enzymes of the liver, are insufficient in many cases. Metabolic disorders that result in diffuse changes in liver texture and size are

Corresponding author: Dr. ARAFAT KHALPHALLAH

E-mail address: arafatvet2003@yahoo.com

Present address: Department of Animal Medicine, Faculty of Veterinary Medicine, Assiut University, Assiut 71526, Egypt. gaining in importance, and hepatic abscesses that cannot be diagnosed clinically develop frequently (Radostits et al., 2007). Braun (1990) stated that a complete ultrasonography evaluation of the liver in cattle should give full detailed description about the size, position, ultrasonographic parenchymal pattern of the liver and localization of blood vessels.

The clinical findings of liver diseases particularly liver abscess were not specific (Radostits et al., 1994; Braun et al., 1995a) and furthermore, the signs of liver dysfunction, such as icterus or bilirubinuria, were not observed in bovine animals (Kremer et al., 1994).

Accordingly, the present study was conducted to establish the ultrasonographic findings of hepatobiliary system in healthy Egyptian buffaloes with special reference to the acoustic windows for the appropriate seats for the footprint of the transducer. Hence, this will be reflected on improving the ability of this technique to identify any abnormal changes in the physical structure of these organs due to any other diseases. 


\section{MATERIALS AND METHODS}

Animals: Thirty buffaloes were included in this study. The female; non-pregnant buffaloes were selected from healthy buffaloes belonging to either the herd of veterinary teaching hospital which kept for teaching purpose or from the neighboring villages around Assiut city. This group includes twenty buffaloes of age ranged between 5 to 7 years and ten heifers with age ranged between 1 to 2.5 years.

Samples: Whole blood and serum samples were collected and all precautions of sample collections and preparation for accurate evaluation of hematological and biochemical indices were taken into consideration according to Otter (2013).

Clinical Examination: All buffaloes underwent a thorough clinical examination described by Jackson and Cockcroft (2008).

Complete blood count (CBC) assessment: A fully automated blood cell counter machine, Medonic CA620 Vet hematology analyzer -Sweden, was used to determine various hematological parameters. Differential leukocytic count (DLC) was determined using four field meander method.

Biochemical assays: Spectrophotometric method using Phillips PyeUnicam spectrophotometer (U.V. Visible Mod. 800) was adopted to determine serum concentrations of liver enzymes: aspartate aminotransferase (AST), $\gamma$ glutamyltranspeptidase(GGT), and alkaline phosphatase (AP), serum total protein, Serum albumin, cholesterol and triglycerides (TG). Serum globulin was determined by subtraction of albumin from total protein and its value used to calculate albumin/globulin ratio (A/G ratio). All kits and reagents were obtained from Spectrum Reagents (Egyptian Company for Biotechnology, Egypt).

Radiographical examination: Radiographic examination was carried out according to the method of Nägeli (1991); Braun et al. (1993a). All radiographic examinations were performed using (Philips, super $80 \mathrm{CP}$ ) fixed radiographic apparatus. 60-70 K.V. and 50-60 M.A.S. were used for radiography of the caudal thoracic and cranial abdominal region with $75-90 \mathrm{~cm}$ F.F.D.

Ultrasonographical examination: Ultrasonographic Examination of Liver and Gall bladder was conducted according to Braun (1990) by using a $3.5 \mathrm{MHz}$ Sector transducer of apparatus (FF Sonic, Model UF-4000, Tokyo, Japan). It was performed on standing nonsedated buffaloes. Clipping of the hair and application of the coupling gel at the proposed area for examination.

Statistical analysis: Data were analyzed using statistical software program (Spsswin, 1997). All data were presented as mean \pm standard deviation (SD).

\section{RESULTS}

\section{Clinical findings:}

The mean of body temperature, respiration; heart rate and ruminal motility were $38.2 \pm 0.64 \dot{\mathrm{C}}, 15 \pm 3$ breaths/min, $67 \pm 10$ beat $/ \mathrm{min}$ and $3 \pm 1$ ruminal cycle/2min, respectively. All the animals were clinically healthy and had not any abnormalities.

\section{Blood picture indices:}

Mean values of total red blood corpuscles count, packed cell volume, haemoglobin concentration and total leukocytic count were 7.54 \pm 2.98 (T/L), 38 \pm 3.24 $(\%), 118 \pm 4.5(\mathrm{~g} / \mathrm{L})$ and $6.71 \pm 1.63(\mathrm{G} / \mathrm{L})$, respectively. Mean values of differential leukocytic count for neutrophils, lymphocytes, monocytes, eosinophils and

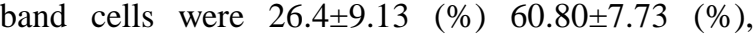
$7.80 \pm 4.63(\%), 3.60 \pm 2.07(\%)$ and $1.40 \pm 0.52(\%)$, respectively.

\section{Serum biochemical analysis:}

Mean values of serum total protein, Albumin, globulin and A/G ratio were $94.7 \pm 10.7(\mathrm{~g} / \mathrm{L}), 55 \pm 8.4$ $(\mathrm{g} / \mathrm{L}), 45.7 \pm 4.6(\mathrm{~g} / \mathrm{L})$ and $1.38 \pm 0.59$, respectively. Meanwhile the mean values of serum levels of GGT, $\mathrm{AP}$ and AST were 14.95 \pm 1.23 (U/L), 36.11 \pm 4.40 (U/L), $32.92 \pm 4.77$ (U/L), respectively. Mean values of serum levels of cholesterol and triglycerides were $10.68 \pm 1.10 \quad(\mathrm{mmol} / \mathrm{L})$ and $3.62 \pm 0.2 \quad(\mathrm{mmol} / \mathrm{L})$, respectively.

\section{Radiographic findings:}

Radiographic finding of reticulum in healthy nonpregnant buffaloes showed that the reticulum was free from any metal objects. The reticulum was imaged as radio-opaque. The diaphragm was imaged as a clear black line between two radio-opaque structures; reticulum and heart. There were no evidences of adhesions between diaphragm and reticulum or between diaphragm and heart. The heart had clear margins, normal size and a characteristic shape. Heart appeared as radio-opaque (Fig. 1). 


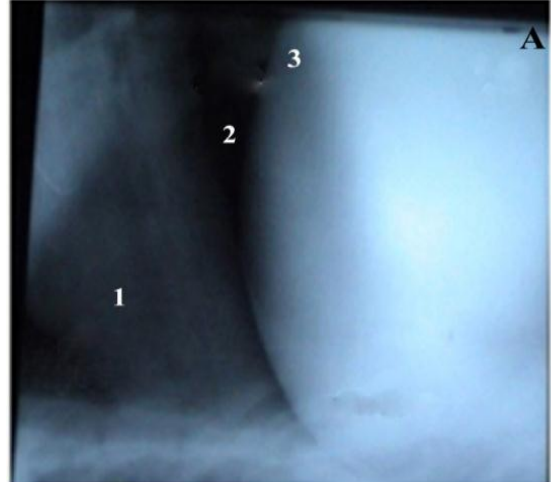
Fig.1 A: Cranial abdominal view 1: Heart. 2: Diaphragm. 3: Reticulum. 4: Sternum

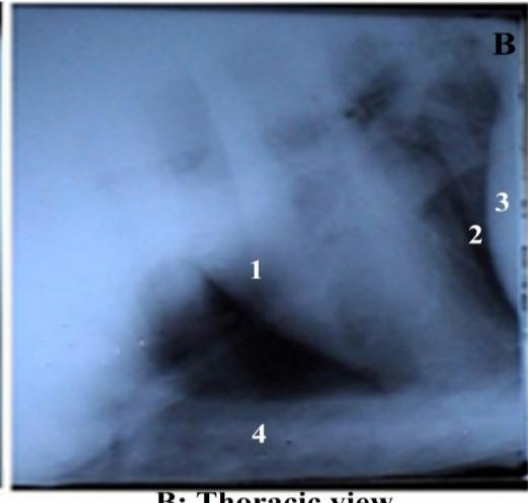

B: Thoracic view

Fig. 1: Lateral radiographic view of the cranial abdomen (a) and the thorax (b) of a 3 years non-pregnant female buffaloes showed normal radiographic appearance of reticulum, heart and diaphragm.

\section{Ultrasonographic findings:}

The liver could beimaged from the right to the median plane of the back and last three intercostal spaces and caudal to costa arch. It was also imaged from the cranial right intercostal spaces particularly 9th ICS with imaging of its caudate lobe. Liver parenchyma was seen as numerous weak echoes evenly distributed on its entire parenchyma. it appears hyperechoic relative to the renal cortex and hypoechoicrelative to the spleen (Fig. 2). The liver course directed caudodorsal to cranioventral, so the ventral margins of the liver at any intercostal space was deeper than the dorsal margin. The liver size was determined by substraction the dorsal margins from the ventral margins. It was ranged from 25 to $30 \mathrm{~cm}$ in the last right three ICSs. It progressively decreased

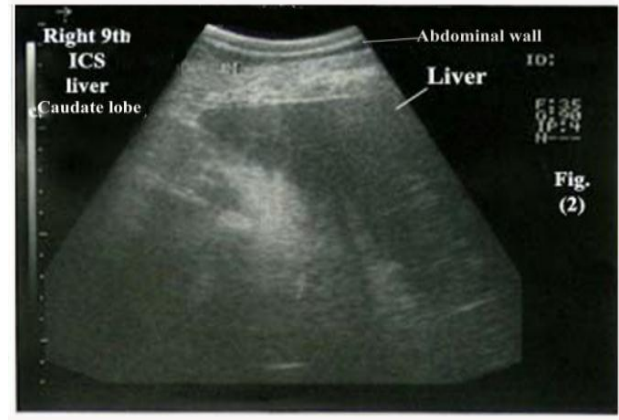

Fig. 2: Ultrasonogram in a buffalo imaged from the right 9 th ICS at a distance $35 \mathrm{~cm}$ from the midline of the back. It showed healthy liver tissue with its caudate lope and the hepatic parenchyma appeared as numerous weak echoes evenly distributed on the entire parenchyma. Its echogenicity was more than that of renal cortex and adrenals.

The portal vein (PV) was situated ventrally and laterally to the caudal vena cava (CVC). It was visualized in the last right three intercostal spaces for a distance about $30 \mathrm{~cm}$ ventral to the dorsal midline of towards the cranial intercostal spaces because of superimposition of the lungs.

The Gall bladder was imaged from the right 10th and 11th ICSs from a distance about $45 \mathrm{~cm}$ from the dorsal midline with width 3 to $4.5 \mathrm{~cm}$. It was not imaged from the right 12 th ICS. The gall bladder was imaged ventromedially to the liver and in close relation to the cranial duodenum. It appeared as black cyst (a fluid filled vesicle) with anechoic lumen and fine echogenic margins and pear shape. Cystic duct imaged as elongated anechoic structure with echogenic wall at the longitudinal section and imaged as a tubular anechoic like structure with echogenic walls in cross section (Fig. 3).

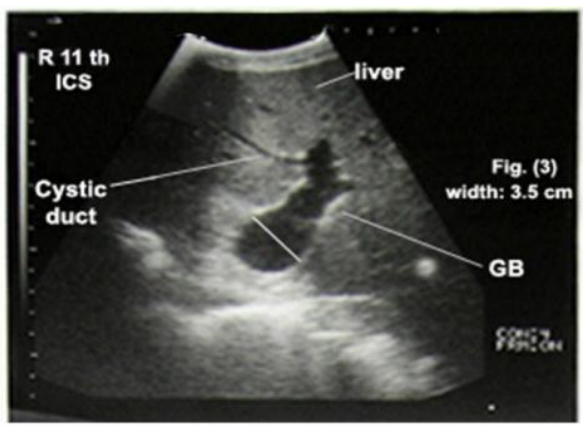

Fig. 3: Ultrasonogram in a buffalo imaged from the right 11th ICS at a distance $45 \mathrm{~cm}$ from the midline of the back. It showed healthy liver tissue and Gall bladder. The Gall baldder was imaged as black cyst (a fluid filled vesicle) with anechoic lumen and fine echogenic margins and pear shape. Its width was about $3.5 \mathrm{~cm}$. CS in its cystic duct imaged as tubular anechoic like structure with echoic walls.

the animal. PV was circular on cross-section and has stellate ramifications into the hepatic parenchyma. Its diameter ranged from 3.25 to $3.7 \mathrm{~cm}$. In contrast to the hepatic veins, the wall of the portal veins was 
easier to be identified because they are characterized by an echogenic border. Differentiation of hepatic and portal veins was only possible in the area of the stellate branching of the portal vein (Fig. 4). Moreover, the diameter of portal vein decreased cranially.

CVC was imaged from the right 11th and 12th ICSs from a distance about 20 cmventral to the dorsal

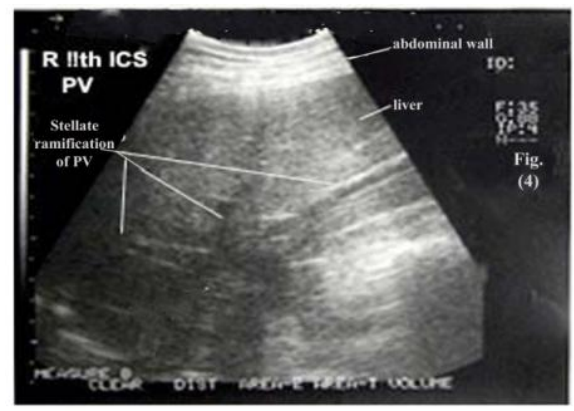

Fig. 4: Ultrasonogram in a buffalo imaged from the right 11th ICS at a distance $30 \mathrm{~cm}$ from the midline of the back. It showed healthy liver tissue and PV. PV appeared circular on cross-section and had stellate ramifications into the hepatic parenchyma. $\mathrm{PV}$ : portal vein.

The hepatic vein (Fig. 5 and 6) and central vein as in (Fig. 7) could be easily imaged from the right 11 th and 12th ICSs. The central vein appeared as anechoic elliptical structure with anechoic margins while the hepatic vein appeared as fork-like with anechoic lumen and ill-defined anechoic margins. The hepatic

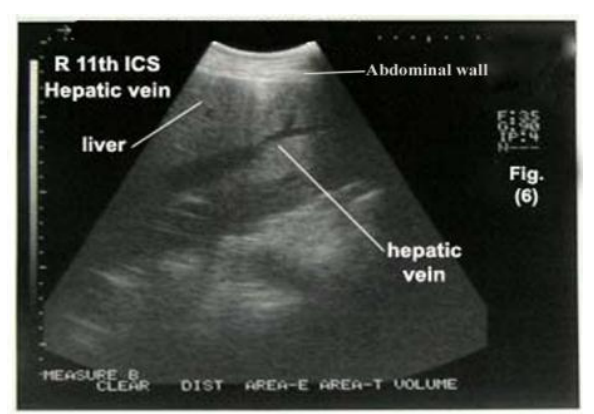

Fig. 6: Ultrasonogram in a buffalo imaged from the right 11 th ICS at a distance $30 \mathrm{~cm}$ from the midline of the back. It showed healthy liver tissue and hepatic vein. The hepatic vein appeared as fork-like structure with anechoic lumen and illdefined anechoic margins.

The common trunk of the left gastric vein and the splenic vein or individual splenic and gastric veins was observed in cross-section before they connected medial to the caudal vena cava and outside of the hepatic parenchyma. These veins were circular on cross-section (Fig. 8). They were imaged as tubular midline. It was not visualized in the other cranial intercostal spaces (10th) because it was obscured by the lungs. It situated more dorsally and medially than the portal vein. Its diameter ranged from 2.8 to 3.1 $\mathrm{cm}$. CVC was triangular in shape. Toward the liver, hepatic veins were seen joining the caudal vena cava (Fig. 5).

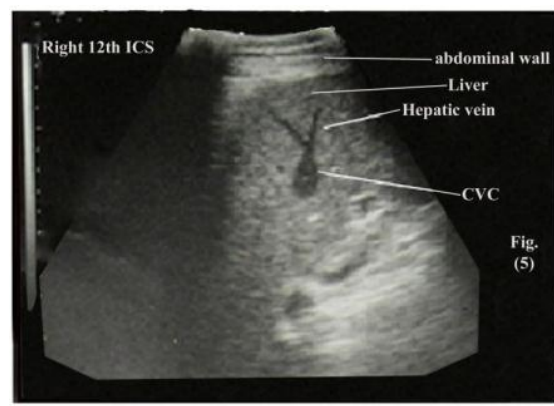

Fig. 5: Ultrasonogram in a buffalo imaged from the right 12th ICS at a distance $20 \mathrm{~cm}$ from the midline of the back. It showed healthy liver tissue with CVC and hepatic vein. CS in the CVC imaged as triangular in shape. The hepatic veins are seen joining the CVC. CVC: caudal vena cava.

vein was imaged at a distance about $20 \mathrm{~cm}$ with CVC or $30 \mathrm{~cm}$ with PV from the dorsal midline particularly from the right 11 th ICS. Meanwhile, the central vein was usually imaged at a distance about $30 \mathrm{~cm}$ from the dorsal midline of the animal.

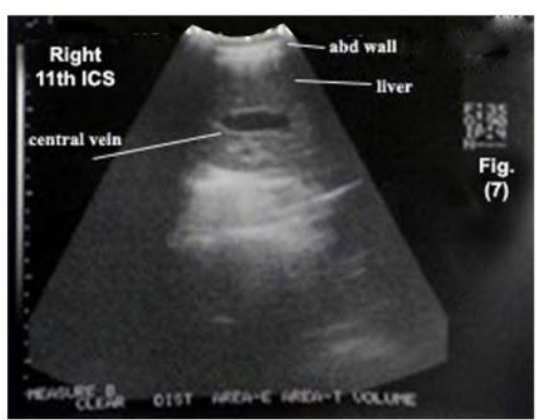

Fig. 7: Ultrasonogram in a buffalo imaged from the right 11th ICS at a distance $30 \mathrm{~cm}$ from the midline of the back. It showed healthy liver tissue and central vein. The central vein appeared as anechoic elliptical structure with anechoic margins.

anechoic or fusiform anechoic structure with anechoic margins in longitudinal-section before they connected, with close relation to the hepatic tissue (Fig. 9). They were imaged from the right 11th ICS at a distance about $20 \mathrm{~cm}$ from the dorsal midline and medially to the CVC. 


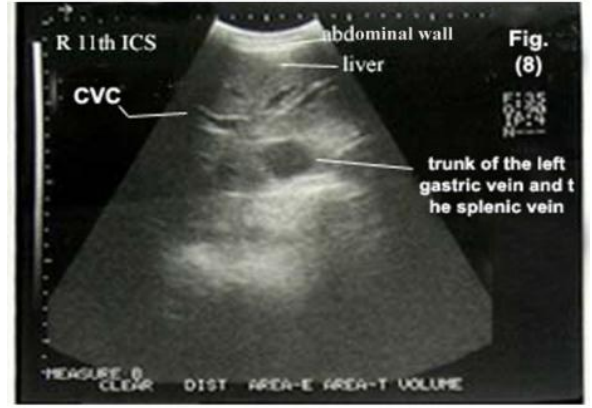

Fig. 8: Ultrasonogram in a buffalo imaged from the right 11th ICS at a distance $20 \mathrm{~cm}$ from the midline of the back. It showed healthy liver tissue with the common trunk of the left gastric vein and the splenic vein that was observed circular in cross-section before they joined, medial to the caudal vena cava and outside of the hepatic parenchyma.

\section{DISCUSSION}

Bovine medicine including diagnosis and therapy is considered the most important field in veterinary medicine in Egypt, because cattle constitute the major sector in animal population if compared with other animal species. Cattle and buffaloes submitted to veterinary medical teaching hospital represent about $90 \%$ from total cases of our patients (El-Sebaie, 2008).

The clinical findings in healthy buffaloes matched with the results reported by Smith (1990); Radostits et al. (1994) while their blood pictures in healthy buffaloes coincided with the normal reference values stated by Sedik (1992); Abd Ellah (1998), meanwhile their blood biochemical levels agreed with what reported by Green et al. (1982); Rosenberger (1990) for total proteins by Abd Ellah (1998) for albumins Salem et al. (2003) for globulins, by Abd Ellah (1998) for A/G ratio, by Sedik (1992) for AST, by Rosenberger (1990) for GGT, AP and cholesterol, by Sedik (1992) for triglycerides.

Braun (1990) stated that a complete ultrasonography evaluation of the liver in cattle should give full detailed description about the size, position, ultrasonographic parenchymal pattern of the liver and localization of blood vessels.

Radiography of the healthy buffaloes showed free reticulum, normal heart and well-identified. The best site for visualization of the liver was the last right three intercostal spaces particularly the 11th ICS because all dimensions of the liver and its related structures could be easily estimated in this ICS. These findings were consistent with the ultrasonographic findings of the liver in cattle the reported by Braun (1990); Khalphallah (2009). The results of this study showed that the best site for visualization of CVC, PV and GB was the right 11th ICS and for a distance about $20 \mathrm{~cm}, 30 \mathrm{~cm}$ and $45 \mathrm{~cm}$ from the dorsal

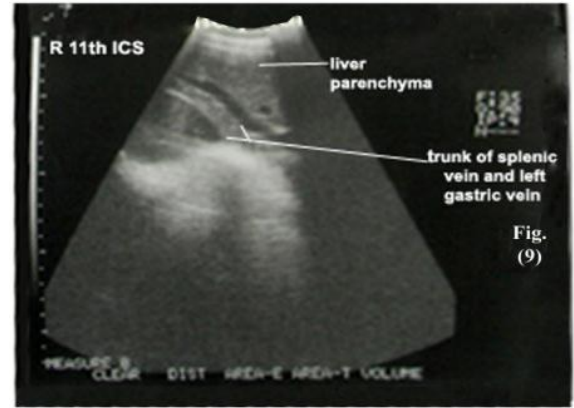

Fig. 9: Ultrasonogram in a buffalo imaged from the right 11th ICS at a distance $20 \mathrm{~cm}$ from the midline of the back. It showed healthy liver tissue with individual splenic and gastric veins were observed as tubular anechoic or fusiform anechoic structure with anechoic margins in longitudinal-section before they connected, with close relation to the hepatic parenchyma.

midline of the animal, respectively which were in consistence with the findings of Braun and Gerber (1992); Braun (1996). Also, the results of this work were similar to the results of the aforementioned authors that declared that the GB was not imaged from the right 12 th ICS, CVC was seldom imaged from the right 10th ICS and was not visualized in the other cranial intercostal spaces because it was obscured by the lungs, and PV is usually visible in the last right three intercostal spaces. The portal vein was situated ventrally and laterally to the caudal vena cava and was circular on cross-section and hadstellate ramifications into the hepatic parenchyma which may facilitate its identification. Differentiation of hepatic and portal veins was only possible in the area of the stellate branching of the portal vein. CVC was triangular in shape. Toward the liver, hepatic veins were seen joining the caudal vena cava. The diameter of PV was ranged from 3.25 to $3.7 \mathrm{~cm}$ while that of CVC was ranged from 2.8 to $3.1 \mathrm{~cm}$. all of the previous results were in agreement with that were reported by Braun (1990); Khalphallah (2009).

This study tried to outstanda full description of the gall bladdersonographically which showed the best site for its visualization and its ultrasonographic appearance. The GB was imaged ventromedially to the liver and in close relation to the cranial duodenum. It appeared as black cyst (a fluid filled vesicle) with anechoic lumen and fine echogenic margins and pear shape with variable diameter depending on the animal feeding status. These results were in agreement with the previous studiesreported by Braun (1990); Braun and Gerber (1992).

The hepatic vein and central veins could be easily imaged from the right 11th and 12th ICSs in this study that also mentioned that central vein was imaged as anechoic elliptical structure without echogenic margins while the hepatic vein appeared as fork-like with anechoic lumen and ill-defined anechoic margins. The hepatic vein could be imaged 
at a distance about $20 \mathrm{~cm}$ with CVC or $30 \mathrm{~cm}$ with PV from the midline of the back particularly from the right 11th ICS. Meanwhile, the central vein was usually imaged at a distance about $30 \mathrm{~cm}$ from the midline of the back. Braun (1990); Braun (1996) mentioned that toward the liver, hepatic veins are seen joining the caudal vena cava. They also added that the common trunk of the left gastric vein and the splenic vein or individual splenic and gastric veins is observed in cross-section before they unite medial to the caudal vena cava and outside of the hepatic parenchyma. These veins are usually circular on cross-section. These findings were matched with the findings reported in this current study. Furthermore, the present study added that splenic and gastric veins were also imaged within close relation to the hepatic tissue.

\section{Conflict of interest statement:}

None of the authors of this paper has a financial or personal relationship with other people or organizations that could inappropriately influence or bias the content of the paper.

\section{ABBREVIATIONS}

A/G ratio: albumin/Globulin ratio, AST: aspartate aminotransferase. AP: alkaline phosphatase, CS: cross section, CVC: caudal vena cava, ICS (s): intercostal space (s), GB: gall bladder, GGT: $\gamma$ glutamyl transpeptidase, PV: portal vein.

\section{ACKNOWLEDGEMENT}

The authors are grateful to the Director of Veterinary Teaching Hospital and Department of Animal Surgery at Assiut University for their kind support during conducting this study.

\section{REFERENCES}

Abd-Ellah, M.R. (1998): Evalution of liver function tests in liver disorders in cattle and buffaloes. Thesis, Master of Veterinary Sciences (Clinical Laboratory Diagnosis), Faculty of Veteriary Medicine, Assiut University, Egypt.

Braun, U. (1990): Ultrasonographic examination of the liver in cows. American Journal of Veterinary Research 51, 1522-1526.

Braun, U. (1996): Ultrasonographic examination of the liver and gallbladder in cows. Part 1.Normal findings. Comp Cont Educ Pract Vet. 18, Supplement Food Animal Medicine and Management S61-S72.

Braun, U. (1997): Atlas und Lehrbuch der Ultraschalldiagnostik beim Rind. Parey Buchverlag, Berlin.

Braun, U. and Gerber, D. (1992): Percutaneous ultrasound-guided cholecystocentesis in cows. American Journal of Veterinary Research 53, 1070-1084.
Braun, U.; Flückiger, M. and Nägeli, F. (1993a): Radiography as an aid in the diagnosis of traumatic reticuloperitonitis in cattle. The Veterinary Record 132, 103-109.

Braun, U.; Götz, M. and Marmier, O. (1993b): Ultrasonographic findings in cows with traumatic reticuloperitonitis. The Veterinary Record 133, 416-422.

Braun, U.; Pusterla, N. and Wild, K. (1995a): Ultrasonographic findings in 11 cows with a hepatic abscess. The Veterinary Record 137, 284-290.

Braun, U.; Pospischil, A.; Pusterla, N. and Winder, C. (1995b): Ultrasonographic findings in cows with cholestasis. The Veterinary Record 137, 537-543

Braun, U.; Marmier, O. and Pusterla, N. (1995c): Ultrasonographic examination of the small intestine of cows with ileus of the duodenum, jejunum or ileum. The Veterinary Record 137, 209-215.

Braun, U.; Wild, K. and Guscetti, F. (1997a): Ultrasonographic examination of the abomasum of 50 cows. The Veterinary Record 140, 93-98.

Braun, U.; Pusterla, N. and Schönmann, M. (1997b): Ultrasonographic findings in cows with left displacement of the abomasum. The Veterinary Record 141, 331-335.

Braun, U.; Iselin, U.; Lischer, C. and Fluri, E. (1998a): Ultrasonographic findings in five cows before and after treatment of reticular abscesses. The Veterinary Record 142, 184189.

Braun, U.; Pusterla, N. and Anliker, H. (1998b): Ultrasonographic findings in three cows with peritonitis in the left flank region. The Veterinary Record 142, 338-340.

Braun, U.; Schweizer, G. and Flückiger, M. (2002): Radiographic and ultrasonographic findings in three cows with reticulo-omasal obstruction due to a foreign body. The Veterinary Record 150, 580-581.

Cornelius, C.E. (1989): Liver Function, Clinical biochemistry of domestic animals, edited by $\mathrm{J}$. J. Kaneko, Fourth Ed. Academic Press, Freeland, pp. 364-391.

El-Sebaie, A.H. (2008): Impact of environmental pollution on animal health and its reflection on the national economy in Egypt. In: Proceeding of Alexander von Humbolat colleagues meeting in Khartoum, Sudan.

Green, S.; Sharon, A.; Jekins, J. and Peggy, Clark A. (1982): A comparative and electrophorotic methods of serum protein determination in clinically normal domestic animals of various ages. Thecornell veterinary journal 72,416 426.

Hassel, D.; Tyler, J.W.; Tucker, R.L. and Sondhof, A.F. (1995): Urachal abscess and cystitis in a 
calf. Journal of Veterinary Internal Medicine 9, 286-288.

Jackson, P. and Cockcroft, P. (2008): Cattle Clinical Examination by Body System and Region. In: Clinical Examination of Farm Animals. First Ed. John Wiley \& Sons, pp. 7-216.

Khalphallah, A. (2009): Comparative studies on ultrasonography and other diagnostic techniques in diagnosis of some digestive system diseases in cattle. Thesis, Master of Veterinary Sciences (Internal veterinary medicine), faculty of Veterinary Medicine, Assiut University, Assiut, Egypt.

Kim, M.; Hwang, K.; Byun, H.; Park, K.; Lee, K.; Han, Y. and Shin, S. (1996): Ultrasonographic appearance of the urinary organs in native Korean cattle. Korean Journal of Veterinary Clinical Medicine 13, 103-107.

Kofler, J. (1996): Arthrosonography: the use of diagnostic ultrasound in septic and traumatic arthritis in cattle-a retrospective study of 25 patients. British Veterinary Journal 152, 683698.

Kremer, H.; Dobrinski, W. and Schreiber, M.A. (1994): Sonographisce Diagnostik. Inner Medizin und angrenzende Gebiete, fourth Ed. Edited by Kremer, H. Dobrinski, W., Urban and Schwarzenberg, München, P 63.

Nägeli, F. (1991): Disseration, VeterinärMedizinische Fackultät der Universität Zürich.

Nyland, T.G. (1984): Ultrasonic patterns of canine hepatic lymphosarcoma. Veterinary Radiolology 25, 167-172.

Nyland, T.G. and Hager, Herring, D.S. (1986): Sonography of the liver, gall bladder, and spleen. Semin. Vet. Med. Surg. (Small Animal) 4, 13-31.

Otter, A. (2013): Diagnostic blood biochemistry and haematology in cattle. In Practice 35, 1 7-16.

Pusterla, N. and Braun, U. (1997): Ultrasonic Examination of The pancrease in healthy cows. Veterinaiy Radiology and Ultrasound 38 (1), 63-67.
Radostits, O.M.; Blood, D.C. and Gay, C.C. (1994): Veterinary Medicine. A text book of the diseases of cattle, sheep, pigs, goats and horses, Eighth Ed. Baillière Tindall, London, $\mathrm{P}$ 323.

Radostits, O.M.; Gay, C.C.; Hinchcliff, K.W. and Constable, P.D. (2007): Veterinary Medicine. A Textbook of the Diseases of Cattle, Horses, Sheep, Pigs and Goats, Tenth Ed. Saunders Elsevier, Philadelphia, pp. 189-382.

Rantanen, N.W. (1986): Diseases of the liver. Veterinary Clinicof North America (Equine Practice); 2: 105-114.

Salem, F.S.; Amany, A.M.; Abd-allah, Azza, Raef, M. and Sahar, N.M. El-Attar, (2003): Immunological, haematological and biochemical studies on cattle naturally infected with some internal parasites. Kafr El-Sheikh Veterinary Medical Journal 1, 47-63.

Schweizer, T.; Sydler, T. and Braun, U. (2003): Kardiomyopathie, Endokarditis valvularis und Perikarditis traumatica beim Rind - Klinische und echokardiographische Befunde an drei Fallberichten. Schweiz Arch Tierheilk 145, 425-430.

Sedik, A.H. (1992): Clinical and Biochemical Studies on fatty liver syndrome in Holstein fresian cows. Thesis, PhD of veterinary Sciences (Internal veterinary medicine and clinical and laboratory diagnosis), faculty of Veterinary Medicine, Assiut University, Egypt.

Sena, N.A.; El-Ghoul, W.S.; Saleh, I.A. and Berbish, E.A. (2003): Clinicopathological, ultrasonographic and pericardiocentesis findings in cattle and buffaloes with traumatic reticuloperitonitis and pericarditis. The Veterinary Medical Journal, Giza 51, 3, 381401.

Smith, B.P. (1990): Text book of Large Animal Internal Medicine. First Ed. Published by C.V. Mosby Company, St. Louis, Philadelphia, USA, pp. 348-367.

Spsswin (1997): Software program for statistical analysis under Windows, USA.

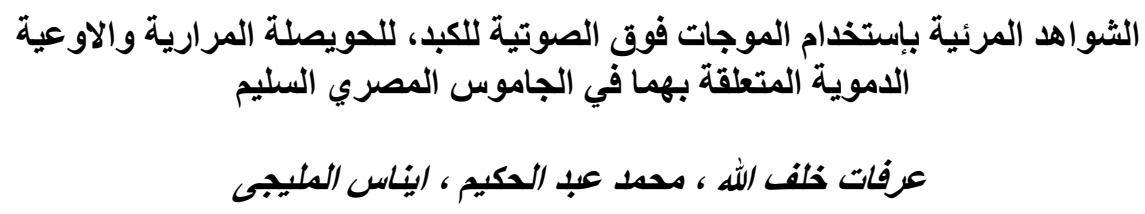

E-mail: arafatvet2003@ yahoo.com_Assiut University web-site: www.aun.edu.eg

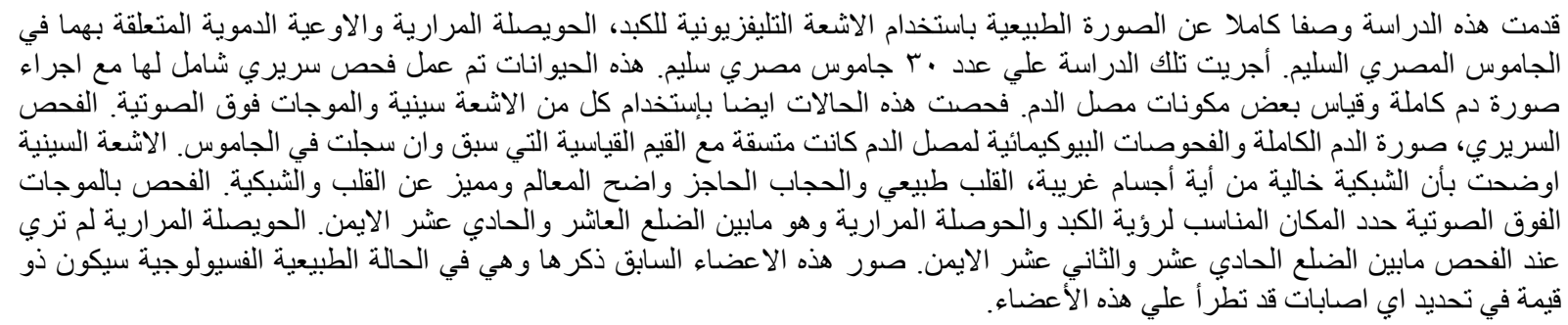

